\title{
What Was, Is No More: Community Pharmacy Economics
}

\author{
Brian Nightengale, RPh, PhD
}

\section{Nightengale's Viewpoint}

T he pharmacy profession has always been dedicated to science, innovation, and providing quality care in their communities. While the practice of pharmacy has continued to evolve, retail community pharmacy arguably has endured the biggest changes and challenges over the past few decades. And today, its business model is facing tremendous pressure.

Many argue that this situation is intensifying to a breaking point and that a new payment model is necessary to ensure the viability of community pharmacies and access to the valuable care they provide. This is particularly the case for independent pharmacies, where the prescription side of their business accounts for $93 \%$ of their revenue. ${ }^{1}$

The rapid expansion of chain, supermarket, mass merchant, and mail order pharmacies during the 1980s and 1990s enabled shoppers across the United States to choose from an array of pharmacy experiences to suit their needs. By 2000, the number of chain drug stores had ballooned to $18,742 .^{2}$ These spacious new stores offered a wider variety of products, drivethrough windows, expanded hours, and other conveniences that drew customers away from their long-standing community establishments. As a result, the number of independent pharmacies serving U.S. communities declined from more than 40,000 stores in 1980 to 20,896 in $2000 .^{2,3}$

In response to increased competition, many independent pharmacies joined forces in advertising co-ops and wholesaler banner programs such as Good Neighbor Pharmacy. ${ }^{4}$ Today, more than $80 \%$ of independent pharmacies belong to a buying group to help them increase scale and drive down costs, whereas banner program membership provides access to advanced business optimization tools. ${ }^{5}$ Also during this time, many independent pharmacies doubled down on what makes them unique: highly personalized and localized care. By tapping into these resources and their entrepreneurial spirit, many independent pharmacies were able to stand strong during this

J Manag Care Spec Pharm. 2020;26(6):703-05

Copyright $\odot 2020$, Academy of Managed Care Pharmacy. All rights reserved. period of increased competition until the industry stabilized in the 2000s.

\section{The Here and Now}

Currently, the 21,767 independent pharmacies that remain make up $35 \%$ of all retail pharmacies in the United States; however, they only account for $20 \%$ of total retail prescription volume. ${ }^{1,6}$ And while competitive pressure from chains still exists, recent consumer trends are creating new opportunities for independent pharmacies to specialize and fill distinct needs in their communities.

Generally speaking, consumers can be segmented into groups by their needs and shopping behaviors. Pharmacies are staking their claim on consumers based on how they define convenience and the care they require. Big box stores and chain pharmacies offer a certain level of convenience for consumers who need to be able to pick up their child's antibiotic late at night or get a refill at an alternative location.

For independent pharmacy shoppers, convenience is defined much differently. It is through the personalized care and expertise of a pharmacist where they derive the most value. For those with complex medication regimens, having a pharmacist who can take the time to explain medications and interactions is a necessity, and that level of care is often less available in a higher-volume retail pharmacy.

The opportunity for quantifiable improvements in health and wellness outcomes is likely to be much greater when patients are fully engaged with their health care professionals. These statistics and changing consumer behaviors bode well for pharmacies that deliver on unique, meaningful interactions with the potential to improve outcomes and reduce physician visits or hospital readmissions. However, the experience is not enough-significant barriers need to be removed for pharmacies before the health care system can realize the many benefits of these enhanced experiences and expanded services.

\section{Massive Industry Pressures}

All pharmacies are faced with the same economic pressures from a reimbursement standpoint. The pharmacy payment model remains structured around filling prescriptions, and 
reimbursement rates for those prescriptions have been shrinking steadily for nearly a decade. ${ }^{7}$

Furthermore, unpredictable fees have become increasingly problematic, particularly direct and indirect renumeration (DIR) fees and generic effective rate (GER) fees. Often collected months after prescriptions are dispensed, their retroactive nature makes it difficult to predict profitability at the point of purchase. DIR fees can exceed $\$ 12$ per prescription and are unfairly and inconsistently applied to pharmacies that have little to no control over the metrics that drive these fees. This financial strain affects all pharmacies and is most problematic with preferred networks, which are also increasingly popular with pharmacy benefit managers (PBMs) and health plan sponsors.

GER fees are set according to discount targets off the average wholesale price (AWP). This is another metric over which the pharmacy has little control, since AWP is set by the manufacturer and reimbursement is set by PBMs according to maximum allowable cost pricing. As a result of these additional retroactive fees, prescriptions that appear to be profitable at the time they are dispensed end up costing pharmacies in the end.

These pressures are further intensified by preferred networks where lower reimbursement and higher DIR fees are exchanged, presumably, for the promise of higher patient volume. Whether or not that promise holds true is subject to debate; however, if patients are driven to a pharmacy because of preferred status, that pharmacy is losing more money on the increased patient volume.

\section{Opportunities and the Need for Change}

While industry pressures mount, there are many opportunities on the horizon that will enable growth, as the need for community-based care continues to increase. If stakeholders in the health care ecosystem are willing to be open-minded, collaborative, and innovative with the role pharmacies play and how they are compensated for the resulting outcomes, then the outlook for community pharmacy will be strong.

By 2032, we will face a shortage of up to 122,000 physicians in the United States. ${ }^{8}$ The nation's population is expected to increase by more than $10 \%$ during this time period, with people aged 65 years and older increasing by $48 \%$. Included in that 65-and-over demographic is more than a third of all the physicians who are currently practicing today. ${ }^{8}$ This means the demand for care services is expected to skyrocket, while an unprecedented number of doctors will be facing retirement.

Community pharmacies are positioned perfectly to fill that gap because of their accessibility and the frequency in which they are visited. On average, high-risk patients see their pharmacists 35 times per year, while visiting their primary care physician only 4 times. ${ }^{9}$ Independent pharmacies, in particular, are positioned to meet the increasing demand for community-based services, including immunizations, pointof-care testing, chronic disease management, and other types of care traditionally provided by a physician.

Today, 93\% of full-line independent pharmacies offer medication synchronization services, and $77 \%$ provide medication therapy management (MTM) services. ${ }^{1}$ Many are also offering patient care services, as well. For example, $76 \%$ of independent pharmacies provide flu immunizations, and $57 \%$ of independent pharmacies monitor blood pressure. ${ }^{1}$

\section{How We Will Get There}

For community pharmacists to fill these growing health care needs, 2 key barriers must be addressed: provider status and reimbursement. First, regulations limiting the scope of practice at the federal and state levels must be modernized to recognize the substantial clinical training that pharmacists receive during and after pharmacy school. Second, the current reimbursement model must be overhauled completely to fairly compensate pharmacies for their dispensing, along with separate compensation for the care and services provided beyond medication dispensing.

When these 2 goals are accomplished, community pharmacies will be able to participate fully in value-based payment models where incentives are aligned around improved patient outcomes and cost efficiency. For example, patients with cardiovascular disease whose medications are synchronized have been shown to be up to 3 times more adherent to their medications, have a 9\% lower rate of hospital visits, and have a 3\% lower rate of outpatient visits than patients whose medications are not synchronized. ${ }^{10}$ This clearly demonstrates the effect pharmacies can have on outcomes and how those efforts deserve to be supported by a reimbursement model that adequately factors in the long-term value of care services and the effect they have on overall health care costs.

When PBMs are incentivized only around the per-memberper-month cost of a prescription, the positive effect that care services can have is overlooked. Therefore, defining value as the lowest dispensing cost shortchanges pharmacies and patients. As Dr. Trygstad notes next in his perspective piece, pharmaceuticals are the most cost-effective form of health care, and the practice of pharmacy can maximize this benefit to the overall system.

Instead of viewing community pharmacies as cost drivers through which savings can be squeezed, PBMs and plan sponsors should look to pharmacies as cost savers that can improve outcomes through efficient, community-based care-and independents are poised to step into this opportunity today.

Perhaps most importantly, consumers and patients agree. J.D. Power began ranking chain drug stores based on customer satisfaction in 2007 and an independent franchise group has won the award every year since its inception, with the Good Neighbor Pharmacy program ranking "Highest in Customer Satisfaction among Chain Drug Stores" 9 times..1

Beyond addressing the physician shortage, independent pharmacies can leverage their unique, high-touch services to amplify their effect on patient outcomes. Layering in medication synchronization, MTM, wellness education, and other adherence-minded services will not only make health care more convenient and effective, but also more valuable to the individual and the community at large. 


\section{Authors}

BRIAN NIGHTENGALE, RPh, PhD, President, Good Neighbor Pharmacy, AmerisourceBergen, Chesterbrook, Pennsylvania.

AUTHOR CORRESPONDENCE: Brian Nightengale, RPh, PhD, President, Good Neighbor Pharmacy, AmerisourceBergen, 227 Washington St., Conshohocken, PA 19428. Tel.: 267.315.1445;

E-mail: BNightengale@amerisourcebergen.com.

\section{DISCLOSURES}

No funding supported the writing of this article. The author is an employee of AmerisourceBergen and leads its Good Neighbor Pharmacy program, which supports independent community pharmacy customers.

\section{REFERENCES}

1. National Community Pharmacists Association. 2019 NCPA Digest: changing the pharmacy payment model. 2019. Available at: http://www.ncpa.co/ pdf/digest/2019/2019-digest.pdf. Accessed April 21, 2020.

2. Fein A. The pharmacy industry's evolution: 2000 to 2010. Drug Channels Institute. September 13, 2011. Available at: https://www.drugchannels. net/2011/09/pharmacy-industrys-evolution-2000-to.html. Accessed April 21, 2020.

3. How the small, neighborhood pharmacy prevails. Triangle Business Journal. April 24, 2017. Available at: https://www.bizjournals.com/triangle/ news/2017/04/24/how-the-small-neighborhood-pharmacy-prevails.html. Accessed April 21, 2020.
4. Leading independent pharmacy buying groups pair up. Pharmaceutical Commerce. Updated March 20, 2017. Available at: https://pharmaceuticalcommerce.com/brand-marketing-communications/leading-independentpharmacy-buying-groups-pair. Accessed April 21, 2020.

5. Fein AJ. 2017 economic report on U.S. pharmacies and pharmacy benefit managers. Drug Channels Institute. February 2017. Available at: http:// drugchannelsinstitute.com/files/2017-PharmacyPBM-DCI-Overview.pdf. Accessed April 21, 2020.

6. IQVIA. Prescriptions and market share report. November 2019 Data/ Rolling 12-Month Rx Count. 2019

7. Fein A. New data: pharmacy owners' profits fall as industry competition rises. Drug Channels Institute. January 9, 2018. Available at: https://www. drugchannels.net/2018/01/new-data-pharmacy-owners-profits-fall.html. Accessed April 21, 2020.

8. Association of American Medical Colleges. New findings confirm predictions on physician shortage. April 23, 2019. Available at: https://www.aamc. org/news-insights/press-releases/new-findings-confirm-predictions-physician-shortage. Accessed April 21, 2020.

9. Moose J, Branham A. Pharmacists as influencers of patient adherence. Pharmacy Times. August 21, 2014. Available at: https://www.pharmacytimes.com/publications/directions-in-pharmacy/2014/august2014/pharmacists-as-influencers-of-patient-adherence-. Accessed April 21, 2020.

10. Krumme AA, Glynn RJ, Schneeweiss S, et al. Medication synchronization programs improve adherence to cardiovascular medications and health care use. Health Aff (Millwood). 2018;37(1):125-33. Available at: https://www. healthaffairs.org/doi/full/10.1377/hlthaff.2017.0881. Accessed April 21, 2020.

11. J.D. Power. Pharmacy customers slow to adopt digital offerings but satisfaction increases when they do, J.D. Power Finds. Press release. August 20, 2019. Available at: https://www.jdpower.com/business/press-releases/2019us-pharmacy-study. Accessed April 21, 2020.

\title{
A Sleeping Giant: Community Pharmacy's Potential Is Unrivaled
}

\author{
Troy Trygstad, PharmD, MBA, PhD
}

\section{Trygstad's Viewpoint}

$\mathrm{P}$ harmacies in the United States filled well over 4 billion prescriptions last year, with more than 3.7 billion of those filled at a community-based pharmacy. ${ }^{1}$ Up against nearly 900 million outpatient visits, 36 million hospitalizations, and 4.5 million home health service users, pharmacy continues to reign as the most

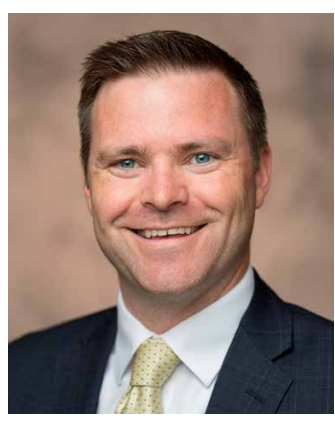

frequent potential service delivery touchpoint in the health care system. ${ }^{2-4}$

Largely untapped, community pharmacies can be the solution to our system's convenience care needs as on-demand walk-in facilities, as well as its chronic care needs as the most reliable, available, and cost-effective "eyes and ears" for the care team.

Not long ago, then Aetna Chief Executive Mark T. Bertolini described community-based pharmacy as the "new front door for health care in America." With consumer acceptance of retail J Manag Care Spec Pharm. 2020;26(6):705-08 Copyright $\odot 2020$, Academy of Managed Care Pharmacy. All rights reserved. sites of care becoming ever more acceptable, we may be on the verge of a significant market evolution. ${ }^{5}$ 